\title{
Cost Estimation for the Pure Electric Family Car's Whole Life Cycle Based on Partial Least Square Regression
}

\author{
Yi Huang ${ }^{\mathrm{a}}$, Kechun Huang ${ }^{\mathrm{b}}$ and Junmin $\mathrm{Wu}^{\mathrm{c}}$
}

Economics and Management School, Jiangsu University of Science \& Technology, Zhenjiang 212003, China

a631692236@qq.com, b1226737630@qq.com, cwujunmin824@163.com

Keywords: Pure Electric Family Car; Whole Life Cycle Cost; Partial Least Square Regression.

\begin{abstract}
The pure electric family car as an example, we use the partial least square regression to get the mapping relationships between design parameters and acquisition costs, operation cost, recycling scrap cost during the phase of design. The calculation results show that remaining mileage and battery capacity are the key factors affecting the cost of pure electric family cars, reasonable chose of remaining mileage and battery capacity can improve the efficiency of pure electric family cars, it will give the correct direction of pure electric family cars in China.
\end{abstract}

\section{Introduction}

In recent years, many scholars both at home and abroad have conducted the research into the whole life cycle cost (LCC) of the battery electric vehicle. From the perspective of economy and energy environmental benefits, some scholars including AMJADS analyzed the economic benefits of the battery electric vehicle and oil-fueled vehicle based on the theory of LCC in 2010[1]. It is found that the former has a higher rate of energy utilization. In 2010, Ai Jianghong compared the influence of the battery electric vehicle and oil-fueled vehicle on the environment based on the theory of LCC [2]. It is pointed out that the battery electric vehicle represents the tendency of the industry. In 2009, some scholars including Ren Yulong took the lead in building a LCC model for the battery electric vehicle from the angle of the consumers [3]. In 2014, some scholars including Wu Tian introduced the present value analysis into the model so as to solve the issue of intertemporal consumption. It is concluded that the LCC of battery electric vehicle is much higher than that of the traditionally oil-fueled bus in China [4]. In 2015, some scholars including Wan Jian built a model for evaluating the economic benefits of the bus based on the theory of the time value of capital [5]. It is concluded that the pure-electric bus has the distinct advantage over the hybrid or oil-fueled bus. With the progress of the battery technology, the battery electric vehicle will gradually display its unique competitiveness.

These researches into the LCC of the battery electric vehicle both at home and abroad have been mainly devoted to the pure-electric bus. According to the comparative analysis between the oil-fueled bus and pure-electric bus, the economic benefits of the latter have been proved. However, there are rare researches into the LCC of the pure electric family car, which is a striking contrast to the soaring demand for the private car in China in recent years. Based on the partial least square regression, this paper has established the mapping relationship between the cost of the pure electric family car and its design parameters. Moreover, the LCC of the pure electric family car has been also estimated. With the key factors influencing the cost identified, the LCC will be controlled effectively. Moreover, the major improvement on the structure of the pure electric family car has been also pointed out so as to facilitate the sound development of the pure electric family car.

\section{The analysis on the LCC of the pure electric family car}

\subsection{The analysis on the LCC model of the pure electric family car}

The Whole life cycle Cost (LCC) has included all the expense involved in the design, development, production, operation, maintenance and liquidation [6]. Few of the existing researches are concerned 
with the cost of the recycle and liquidation of the pure electric family car from the angle of LCC, which means that it has not been included in the list of cost. Based on the cost of carry model, this paper will divide the LCC of the pure electric family car into the purchase cost, operation-maintenance cost and recycle-liquidation cost. The purchase cost means the expense for the car price and relevant activities. The operation-maintenance cost means the expense involved in the operation, repair and maintenance of the car. It can be classified as the energy consumption expense or non-energy consumption expense. The majority of the energy consumption expense has mainly taken the form of charge cost. Besides the expense for battery replacement and part repair, the non-energy consumption expense has covered the insurance, road maintenance and toll. The recycle-liquidation cost includes the expense after the pure electric family car reaching to the end of service life. The earning from the scrape recycle should be also deducted from the expense.

\subsection{The choice of the LCC estimation method for the pure electric family car}

According to the relevant data, the design expense has only accounted for about 5 percent of the LCC. However, more than 70 percent of the total product cost can be determined at the design stage [7]. Hence, the stage of product design is critical to the cost estimation. The LCC estimation of battery electric vehicle has been faced with those problems below. Firstly, the application of LCC concept to the manufacturing of pure electric family car has remained at the early stage, which means that the historical data is difficult to obtain. The sample is also small in size. Secondly, there are a variety of design parameters which have been subject to the collinearity. Thirdly, the mapping relationship between LCC and design parameters is expected. All things considered, this paper has chosen the partial least square regression for the cost estimation. It is a method of parameter estimation which is applicable to the early stage of LCC. It has also integrated the advantages of multiple regression analysis, canonical correlation analysis and principal component analysis. The features of the method are presented as follows. Firstly, it can overcome the colinearity and also support the regression estimation. Secondly, it can support the estimation with the limited sample. Thirdly, all variables selected will be retained in the final estimation model [8].

\section{The LCC estimation of the pure electric family car based on the partial least square regression}

\subsection{The diagnosis of the colinearity between variables}

Variance Inflation Factor (VIF) is a method aimed to judge the colinearity between independent variables. The formula of VIF is $V I F_{j}=\left(1-R_{j}^{2}\right)^{-1} . R_{j}$ means the multiple correlation coefficient of the independent variable $X_{j}$ towards the regression of other independent variables. In the case of $V I F_{j} \geq 10$, it will influence the accuracy of estimation.

\subsection{The building of the regression model for the partial least square regression}

(1) The principle of the partial least square regression model

Given the dependent variable $Y=\left[y_{1}, y_{2}, \cdots, y_{p}\right]$ and independent variable $X=\left[x_{1}, x_{2}, \cdots, x_{p}\right]$, there are a total of $\mathrm{n}$ sample points. The first component of the partial least square $t_{1}$ will be extracted from $x$. The first component of the partial least square $u_{1}$ will be extracted from $Y$. $t_{1}$ and $u_{1}$ should satisfy the following two conditions at the same time.

a) They should represent the variable information in $X$ and $Y$ as much as possible.

b) The degree of correlation between them should reach the maximum.

After the extraction of $t_{1}$ and $u_{1}$, the regression of $x$ to $t_{1}$ and $Y$ to $u_{1}$ will be made. If the equation can gain the satisfying accuracy, the algorithm will cease. If not, the second extraction of the principal component will be carried out until the satisfying accuracy is achieved. If the m components are gained $\left(t_{1}, t_{2}, \cdots, t_{m}\right)$, the regression of the $y_{1}, y_{2}, \cdots, y_{q}$ and $t_{1}, t_{2}, \cdots, t_{m}$ will be made, representing the functional relationship between $y_{1}, y_{2}, \cdots, y_{q}$ and $x_{1}, x_{2}, \cdots, x_{p}$. 
(2) The steps of building the regression model for the partial least square regression

a) The matrix $X$ for the indepednent vairable and the matrix $Y$ for the dependent variables will be standardized, thus leading to the $X_{0}$ and $Y_{0}$.

b) One principal component $t_{1}$ and $u_{1}$ will be extracted from $X_{0}$ and $Y_{0}$.

$$
t_{1}=X_{0} w_{1}, u_{1}=Y_{0} v_{1} .\left\|w_{1}\right\|^{2}=1\left\|u_{1}\right\|^{2}=1
$$

The regression of $X_{0}$ and $Y_{0}$ to $t_{1}$ will be made

$$
X_{0}=p_{1} t_{1}+E_{1}, Y_{0}=r_{1} t_{1}+F_{1}
$$

is the regression coefficient. $E_{1}$ and $F_{1}$ are the residual matrix which is used to check the convergence. If the satisfying progress is made, it will move on to the next step. If not, $E_{1}$ and $F_{1}$ will replace $X_{0}$ and $Y_{0}$ to extract the second principal component $t_{2}$. The steps above will be repeated until the satisfying accuracy is gained.

c) If the m components are gained $\left(t_{1}, t_{2}, \cdots, t_{m}\right)$, the regression of the $X_{0}$ and $Y_{0}$ to the $t_{1}, t_{2}, \cdots, t_{m}$ will be made.

$$
X_{0}=t_{1} p_{1}+t_{2} p_{2}+\cdots+t_{m} p_{m}+E_{m}, Y_{0}=t_{1} r_{1}+t_{2} r_{2}+\cdots+t_{m} r_{m}+F_{m}
$$

Given the standardized variables $X_{i}^{*}(i=1,2, \cdots, m)$ and $Y_{i}^{*}(j=1,2, \cdots, r)$, considering that $t_{1}, t_{2}, \cdots, t_{m}$ is the linear combination of $x_{1}, x_{2}, \cdots, x_{p}$, a total of $p$ regression equations will be gained for the standardized variables.

$$
Y_{j}^{*}=\alpha_{j 1} X_{1}^{*}+\alpha_{j 2} X_{2}^{*}+\cdots+\alpha_{j m} X_{m}^{*}
$$

According to the reverse process of the standardization, the regression equation of $Y_{i}^{*}$ will be reduced to the regression equation of $Y$ in relation to $X$.

\subsection{The source of the data and the selection of the index}

With the pure electric family car chosen as the research object, the vehicle parameters determined in the design stage have included the vehicle body parameter, electric motor parameter and battery parameters. The vehicle body parameters have included the length, width, height, and air quality. The electric motor parameters have included the maximum torque, maximum power and maximum rotation. The battery parameters have included the rated battery capacity and maximum endurance mileage. In addition, the questionnaire over the importance of the design parameters of the pure electric family car has been carried out among the users of private car. A total of 8 indexes have been chosen, namely the length, height, width, maximum power, maximum torque, equipment quality, endurance mileage and rated battery capacity.

The relevant information has not been released by the automobile companies. Moreover, it is quite difficult to collect the information and historical data regarding the cost of the pure electric family car. Therefore, this paper has chosen the questionnaire to obtain the external data. From the perspective of the purchaser, the LCC of the pure electric family car will be divided into the purchase cost, operation-maintenance cost and recycle-liquidation cost. Through the questionnaire, the relevant data regarding 9 brands of pure electric family car has been collected. Various design parameters have been collected in the online automobile websites.

The operation-maintenance cost of the pure electric family car can be classified as the energy consumption expense and the non-energy consumption expense, as seen in the table 1.

The energy consumption expense is mainly made up of the electricity cost. The non-energy consumption expense has included the tax, repair, maintenance, replacement and fine. This paper is mainly concerned with the electricity cost and battery maintenance which are directly related to the design parameters. The relationship between design parameters and operation cost will be also analyzed. 
Table 1 the operation-maintenance cost of the pure electric family car

\begin{tabular}{|c|c|}
\hline $\begin{array}{c}\text { Energy } \\
\text { consumption } \\
\text { expense }\end{array}$ & Electricity cost \\
\hline $\begin{array}{c}\text { Non-energy } \\
\text { consumption } \\
\text { expense }\end{array}$ & $\begin{array}{c}\text { Purchase tax, Vehicle and vessel use tax, compulsory traffic accident liability insurance, } \\
\text { annual examination, commercial insurance, road maintenance tax, battery replacement } \\
\text { and maintenance, part repair and maintenance and traffic fines }\end{array}$ \\
\hline
\end{tabular}

With regard to the electricity cost, those users with an annual mileage below $8000 \mathrm{KM}$ will be excluded from the survey. The rest of the data will be recorded. Supposed that the vehicle service life is 10 years, the sample data is shown in the table 2. In most cases, the cost for recycle and liquidation is negative. It is the residual value earning after the liquidation of the pure electric family car. Some people note that it should account for 4 percent of the purchase cost for the hybrid vehicle [9]. Considering that there is a large amount of recycle metal, such as the lithium, manganese and nickel, in the used battery of the pure electric family car, the recycle-liquidation cost will comprise 6 percent of the purchase cost of the pure electric family car in this paper.

Table 2 The parameters of the battery electric vehicle and the data regarding the purchase cost, operation-maintenance cost and recycle-liquidation cost

\begin{tabular}{|c|c|c|c|c|c|c|c|c|c|c|c|}
\hline Brand & $\begin{array}{c}\text { Purchase } \\
\text { cost } \\
\text { (Yuan) }\end{array}$ & $\begin{array}{c}\text { Operation- } \\
\text { maintenanc } \\
\text { e cost } \\
\text { (Yuan) }\end{array}$ & $\begin{array}{c}\text { Recycle- } \\
\text { Liquidatio } \\
n \\
\text { cost } \\
\text { (Yuan) } \\
\end{array}$ & $\begin{array}{c}\text { Lengt } \\
\mathrm{h} \\
(\mathrm{mm})\end{array}$ & $\begin{array}{l}\text { Width } \\
\text { (mm) }\end{array}$ & $\begin{array}{l}\text { Heigh } \\
\mathrm{t}(\mathrm{mm})\end{array}$ & $\begin{array}{c}\text { Maximum } \\
\text { power } \\
(\mathrm{kW})\end{array}$ & $\begin{array}{l}\text { Maximum } \\
\text { torque } \\
(\mathrm{N} \cdot \mathrm{m})\end{array}$ & $\begin{array}{l}\text { Equipmen } \\
\text { t quality } \\
\text { (kg) }\end{array}$ & $\begin{array}{l}\text { Enduranc } \\
\text { e mileage } \\
\quad(\mathrm{km})\end{array}$ & $\begin{array}{c}\text { Battery } \\
\text { capacit } \\
y \\
(\mathrm{kWh})\end{array}$ \\
\hline $\begin{array}{l}\text { Sai } \\
\text { ou }\end{array}$ & 214500 & 219200 & -12870 & 2947 & 1690 & 1507 & 85 & 510 & 1385 & 200 & 21.4 \\
\hline Smart & 259200 & 218100 & -15552 & 2695 & 1559 & 1565 & 55 & 130 & 750 & 145 & 17.6 \\
\hline $\begin{array}{c}\text { Yi } \\
\text { dong }\end{array}$ & 237800 & 225300 & -14260 & 4620 & 1820 & 1515 & 45 & 280 & 1610 & 200 & 20 \\
\hline $\begin{array}{l}\text { Chen } \\
\text { feng }\end{array}$ & 206900 & 229700 & -12414 & 4467 & 1771 & 1576 & 80 & 254 & 1494 & 175 & 24 \\
\hline $\begin{array}{l}\text { Yun } \\
100\end{array}$ & 145200 & 163500 & -8712 & 3559 & 1620 & 1476 & 18 & 120 & 968 & 150 & 18 \\
\hline $\begin{array}{c}\text { BYD } \\
\text { E6 }\end{array}$ & 370600 & 399870 & -22236 & 4560 & 1822 & 1645 & 92 & 450 & 2380 & 300 & 57 \\
\hline $\begin{array}{l}\text { Jiang } \\
\text { Huai }\end{array}$ & 183600 & 175600 & -11016 & 4320 & 1710 & 1515 & 50 & 215 & 1260 & 240 & 23 \\
\hline QQ & 159700 & 215600 & -9582 & 3564 & 1620 & 1527 & 41.8 & 150 & 1128 & 200 & 22.3 \\
\hline Bei qi & 317400 & 294800 & -19044 & 4861 & 1820 & 1462 & 80 & 255 & 1760 & 210 & 28 \\
\hline
\end{tabular}

As seen in the table 2, the operation-maintenance cost has mainly included the electricity cost and battery-replacement cost. The electricity cost for the service life of 10 years can be calculated as follows. Electricity cost $=\bar{A} \times B \times C$ cost.

means the electricity comsuption $(\mathrm{kW} \cdot \mathrm{h})$ for the coverage of 100 miles. $C$ means the unit price of the eletricity (Yuan/ $\mathrm{kW} \cdot \mathrm{h}$ ). $B$ means the mileage of the private car during the 10 years. It is calculated as $B=D_{i} \times 365 \times 10 / 100$. $D_{i}$ is the daily mileage of the private car. After the correlation analysis of the data in the table 2, the correlation coefficient between the cost (purchase, operation-maintenance and recycle-liquidation) and the 8 influencing factors will be gained (see table 3). 
Table 3 Correlation coefficient matrix

\begin{tabular}{|c|c|c|c|c|c|c|c|c|c|c|c|}
\hline variable & $\mathrm{X} 1$ & $\mathrm{X} 2$ & X3 & $\mathrm{X} 4$ & $\mathrm{X} 5$ & & & & & & Y3 \\
\hline X1 & 1.00 & 0.88 & 0.07 & 0.25 & 0.113 & 0.13 & 0.72 & 0.54 & 0.54 & 0.44 & -0.12 \\
\hline $\mathrm{X} 2$ & & 1.00 & 0.12 & 0.55 & 0.56 & 0.89 & 0.62 & 0.62 & 0.58 & 0.61 & -0.07 \\
\hline $\mathrm{X} 3$ & & & 1.00 & 0.42 & 0.34 & 0.42 & 0.52 & 0.56 & 0.52 & 0.63 & -0.24 \\
\hline $\mathrm{X} 4$ & & & & 1.00 & 0.76 & 0.67 & 0.51 & 0.63 & 0.71 & 0.71 & -0.22 \\
\hline $\mathrm{X} 5$ & & & & & 1.00 & 0.70 & 0.61 & 0.52 & 0.50 & 0.56 & -0.07 \\
\hline $\mathrm{X} 6$ & & & & & & 1.00 & 0.83 & 0.88 & 0.75 & 0.86 & -0.30 \\
\hline $\mathrm{X} 7$ & & & & & & & 1.00 & 0.53 & 0.59 & 0.72 & -0.52 \\
\hline $\mathrm{X} 8$ & & & & & & & & 1.00 & 0.83 & 0.95 & -0.49 \\
\hline Y1 & & & & & & & & & 1.00 & 0.92 & -0.36 \\
\hline Y2 & & & & & & & & & & 1.00 & -0.49 \\
\hline Y3 & & & & & & & & & & & 1.00 \\
\hline
\end{tabular}

Table 4 The diagnosis of variance inflation factor

\begin{tabular}{|c|c|c|c|c|c|c|c|c|}
\hline variable & $\mathrm{X} 1$ & $\mathrm{X} 2$ & $\mathrm{X} 3$ & $\mathrm{X} 4$ & $\mathrm{X} 5$ & $\mathrm{X} 6$ & $\mathrm{X} 7$ & $\mathrm{X} 8$ \\
\hline $\begin{array}{c}\text { Variance inflation } \\
\text { factor inflation factor }\end{array}$ & 48.08 & 4.16 & 20.98 & 6.99 & 49.26 & 130.58 & 9.76 & 36.72 \\
\hline
\end{tabular}

As seen in the table 3 and 4, there is a significant correlation between the cost (purchase, operation-maintenance and recycle-liquidation) and the design parameters.

\subsection{The determination of partial least square regression equation}

With the aid of Matlab, the partial least square regression analysis on the data in the table 1 will be carried out. Hence, the standardized model of partial least square regression for the 8 independent variables has been made.

Table 5 the analysis on the influence of public factors

\begin{tabular}{|c|c|c|c|c|}
\hline \multirow{2}{*}{ Pubic factors } & \multirow{2}{*}{ index } & \multicolumn{3}{|c|}{ The absolute value of the influence on the cost } \\
\cline { 3 - 5 } & & Purchase cost F1 & $\begin{array}{c}\text { Operation-maintenanc } \\
\text { e cost F2 }\end{array}$ & $\begin{array}{c}\text { Recycle-liquidatio } \\
\text { n cost F3 }\end{array}$ \\
\hline W1 (volume) & X1、X2、X3 & $244.1(9.30 \%)$ & $267.8(8.58 \%)$ & $-5.5(4.79 \%)$ \\
\hline W2 (electric motor) & X4、X5 & $427.0(16.26 \%)$ & $457.0(14.65 \%)$ & $-6.4(5.57 \%)$ \\
\hline W3 (weight) & X6 & $22.3(0.85 \%)$ & $23.90(0.77 \%)$ & $-0.3(0.26 \%)$ \\
\hline W4 (battery) & X7、X8 & $1932.6(73.59 \%)$ & $2371.2(76.00 \%)$ & $-102.7(89.38 \%)$ \\
\hline
\end{tabular}

Due to the interaction between design parameters, the influence of the single variable on the cost of the pure electric family car should not be considered in isolation. As shown in the regression of the partial least square regression equation in the table 6, the influence of the public factors on the cost can be listed in the descending order at the all stages from car purchase, use to liquidation. It can be listed as the battery, electric motor, volume and weight. At the stage of purchase, the influence degree of the battery on the purchase cost has reached 73.59 percent, thus playing a critical role in determining the purchase cost. The two public factors of electric motor and volume have also contributed to 16.26 percent and 9.30 percent of the influence. The factor of weight has only contributed to 0.85 percent of the influence. At the stage of use, the influence degree of the electric motor, volume and weight has experienced the slight decrease. In contrast, the influence of the battery has increased by 2.41 percent. At the stage of recycle and liquidation, those public factors are negatively related to the cost. The factor of battery has played a critical role. The public factors of electric motor, volume and weight have exerted the limited influence. It can be seen that the battery performance should be seen as the top priority at the stage of design so as to reduce the LCC of the pure electric family car. Due attention should be given to the electric motor, volume and weight. 


\subsection{The analysis on the fitting effect of the regression equation}

At the stage of designing the pure electric family car, the product information available is not complete. Some data is quite difficult to obtain, thus leading to the error of cost estimation between minus 30 percent and plus 50 percent. As more product information is gained, the data regarding the historical cost of similar products has been applied to the cost estimation. The range of error has decreased and fallen between minus 15 percent and plus 30 percent [10]. The fitting on the purchase cost, operation-maintenance cost and recycle-liquidation cost of the pure electric family car will be made through the regression equation. The estimation value will be also compared with the actual value, as seen in the figure 1 . The mean absolute percentage error of the regression equation is 0.2642 , 0.1059 and 0.2167 (below 30 percent), which means that a high degree of accuracy has been achieved.
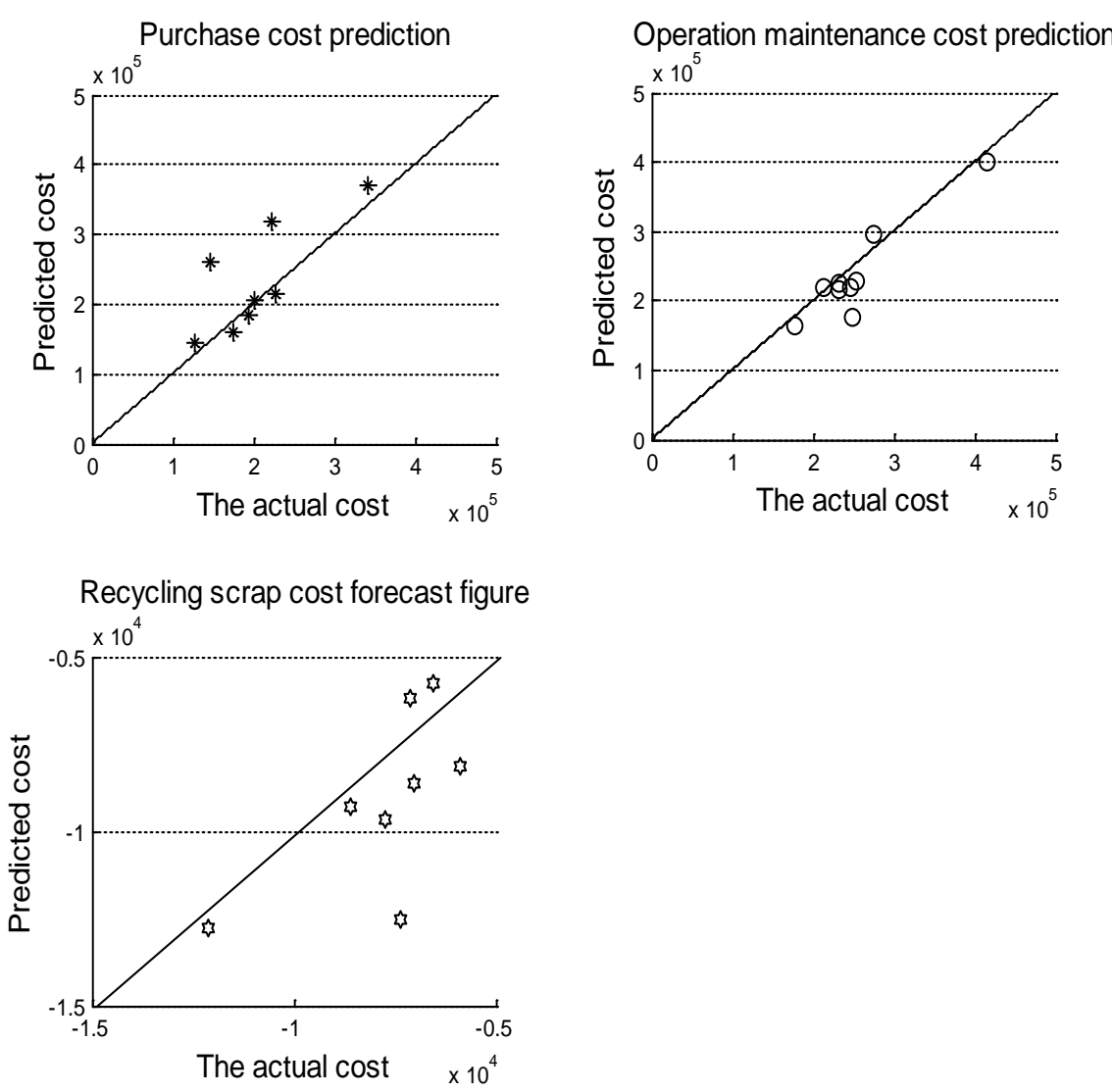

Figure 1 the fitting of the purchase cost, operation-maintenance cost and recycle-liquidation cost

\section{Conclusion and inspiration}

\subsection{Conclusion}

(1) There is a high level of colinearity between the design parameters of the pure electric family car. If only the multiple linear regression is used to research the influence of the design parameter on the LCC, it will not lead to a robust model. It will even result in the wrong parameter estimation. The partial least square regression can overcome the colinearity between the variables in the form of data decomposition and screening. Compared with the multiple linear regression and principal component analysis, it can achieve the estimation with a higher degree of accuracy.

(2) The battery capacity and endurance mileage are the two key factors influencing the cost of the pure electric family car. According to the research result, each design parameter will have different degrees of influence on the purchase cost, operation-maintenance cost and recycle-liquidation cost of the pure electric family car. The endurance mileage and battery capacity will have a major influence on the LCC. Both of them are significantly and positively related to the cost. For the ordinary private car with a daily mileage less than $50 \mathrm{KM}$, the capacity of on-board battery should be chosen properly 
based on the actual need of the consumers. It can not only improve the economic benefits of the car but also help realize the light-weight vehicle.

\subsection{Inspiration}

China should not blindly follow the development path of black-energy automobile adopted by those developed countries. Due to the serious damage to the environment and the drain of black energy, it can not offer a sustainable and environment-friendly approach to solving the energy crisis. Hence, great efforts should be made to research and develop the new-type battery material and relevant technologies. Moreover, the necessary support and guidance of governmental policies should be also provided. From the perspective of overall strategy, further efforts should be made to develop the pure electric family car powered by the renewable energy as well as gain the competitive advantage for the technology and market. For a long time, China has resorted to exchanging the market for the technology. Although many domestic automobile brands have sought to introduce, absorb and innovate in the foreign technologies, they have not yet built a competitive brand in the international market. Therefore, it can help those domestic automobile brands catch up with the foreign counterparts as well as bring convenience to the life of those consumers.

\section{References}

[1] Amjad S, Neelakrishnan S, Rudramoorthy R. Review of design considerations and technological challenges for successful development and development of plug-in hybrid electric vehicles[J].Renewable and sustainable Energy Reviews. 14 (2010) 1104-1110.

[2] Ai Jianghong, Li Haifeng,Lin Jianjun. Analysis on Impact of Electric Vehicle on Environment in Total Life-cycle, Technology Economics. 29 (2010) 35-39.

[3] Ren Yulong, Li Haifeng, Sun Rui, Analysis on Model of Life Cycle Cost of Electric Vehicle Based on Consumer Perspective, Technology Economics. 28 (2009) 54-58.

[4] Wu Tian,Ou Xunmin, Lin Chentao, Analysis on the Whole-Life-Cycle Cost of Battery Electric City-bus from the Consumer Perspective. 34 (2012) 1150-1154.

[5] Wan Jian, Ji Jinzhang, Wang Weifeng, Analysis on economy of New Energy Bus Considering Time Value of Funds, Journal of Highway and Transportation Research and Development. 32 (2015) 154-158.

[6] Shui Kuaili. Product life cycle cost control: the status quo, problems and way out, Cai Kuai Yue Kan. 16 (2015) 21-25.

[7] Chen Xiaochuan, Yuan Die, Wu Di.Cost estimation and performance index for the whole life cycle family car based on neural network integration, Journal of Machine Dedign. 27 (2010) 5-9.

[8] ZHANG Bing, SHEN Fan, CHEN Nan, Relationship between Meteorological Factors and Parameters of Air Quality in Wuhan by Partial Least Squares Regression, Journal of Environmental \& Occupational Medicine. 31 (2014) 241-246.

[9] Qi Tianyu, Ou Xunmin Zhang Xinliang, the Economic Analysis of the Development of HEV Bus in China. China Soft Science, (2009) 102-106.

[10]Han Qinglan, Huang Feng, The Research on the Optimation of Family car Design Based on LCC, Science and Technology Management Research. 03 (2015) 34-38. 